\title{
A Bayesian Network Meta-Analysis of First-Line Treatments for Non-Small Cell Lung Cancer with High Programmed Death-Ligand 1 Expression
}

\author{
Jung Han Kim', Soo Young Jeong,,4, Jae-Jun Lee ${ }^{3,4}$, Sung Taek Park2,4,*, Hyeong Su Kim 1,4,* \\ 1 Division of Hemato-Oncology, Department of Internal Medicine, Kangnam Sacred-Heart Hospital, Hallym \\ University Medical Center, Hallym University College of Medicine, Seoul, Republic of Korea; harri- \\ cil@hallym.or.kr (J.H.K.) \\ 2 Department of Obstetrics and Gynecology, Kangnam Sacred-Heart Hospital, Hallym University Medical \\ Center, Hallym University College of Medicine, Seoul, Republic of Korea; sygy19@hallym.or.kr (S.Y.J.) \\ 3 Departments of Anesthesiology and Pain Medicine, Chuncheon Sacred-Heart Hospital, Hallym University \\ Medical Center, Hallym University College of Medicine, Chuncheon, Republic of Korea; ilo- \\ veu59@hallym.or.kr(J.J.L.) \\ 4 Institute of New Frontier Research Team, Hallym University, Chuncheon, Republic of Korea. \\ * Correspondence: nep2n@hallym.or.kr (H.S.K.), parkst96@naver.com (S.T.P.)
}

\begin{abstract}
We performed this Bayesian network meta-analysis (NMA) to suggest frontline treatments for patients with high PD-L1 expression (at least 50\%). A total of 5,237 patients from 22 studies were included in this NMA. In terms of progression-free survival, immune checkpoint inhibitors (ICIs) plus bevacizumab plus chemotherapy had the highest surface under the cumulative ranking curve (SUCRA) value (98.1\%), followed by ICI plus chemotherapy $(82.9 \%)$. In terms of overall survival (OS), dual immunotherapy plus chemotherapy had the highest SUCRA value (79.1\%), followed by ICI plus bevacizumab plus chemotherapy (73.4\%). However, there was no significant difference of survival outcomes among treatment regimens combined with immunotherapy. Moreover, ICI plus chemotherapy failed to reveal a significant OS superiority to ICI monotherapy (hazard ratio $=0.978,95 \%$ credible internal: $0.771-1.259)$. In conclusion, this NMA indicates that ICI plus chemotherapy with/without bevacizumab might to be the best options in terms of OS for NSCLC with high PD-L1 expression. Considering there was no significant difference of survival outcomes among treatment regimens incorporating immunotherapy and ICI plus chemotherapy failed to show significant survival benefits over ICI monotherapy, however, ICI monotherapy may be reasonable as first-line treatment for advanced NSCLC with high PD-L1 expression and no targetable aberrations.
\end{abstract}

Keywords: non-small-cell lung cancer; immune checkpoint inhibitor; Bayesian meta-analysis; Review

\section{Introduction}

Lung cancer is the leading cause of cancer-related death all over the world [1,2]. For a long time, platinum-based doublet chemotherapy was the first-line standard treatment for patients with advanced non-small-cell lung cancer (NSCLC) without driver somatic mutations. Recently, cancer immunotherapy has been established as a new treatment option for many solid tumor types, including advanced NSCLC [3,4]. Immune checkpoint inhibitors (ICIs) refer to monoclonal antibodies (mAbs) engineered to block co-inhibitory molecules such as CTLA-4, anti-programmed death-1 (PD-1), and PD-ligand 1 (PD-L1) and restore antitumor immunity [5,6]. Randomized trials have revealed that anti-PD-1 mAbs (pembrolizumab and nivolumab) and anti-PD-L1 mAb (atezolizumab) provides additional benefits in both overall survival (OS) and progression-free survival (PFS) for patients with previously treated advanced NSCLC, compared with chemotherapy [7-11]. ICIs are also recommended as a first-line treatment for advanced or metastatic NSCLC, either as monotherapy or in combination with chemotherapy or other targeted agents, based on histology, genetic alterations, and level of PD-L1 expression [12-36]. 
The level of PD-L1 expression is currently the best predictive biomarkers for efficacy of ICIs in advanced NSCLC, although its predictive power is limited, especially in the combination treatment with cytotoxic agents. Approximately $25-35 \%$ of advanced NSCLC cases are expected to test positive for PD-L1 in at least $50 \%$ of tumor cells by immunohistochemistry (IHC) $[7,12,21]$. ICI monotherapy (pembrolizumab, atezolizumab, and cemiplimab) has significantly improved survival outcomes (PFS or OS) compared with chemotherapy in the first-line treatment for advanced NSCLC with PD-L1 expression of at least $50 \%$ and without epidermal growth factor receptor (EGFR), anaplastic lymphoma kinase $(A L K)$, or ROS oncogene 1 (ROS1) aberrations [12,21,24].

Currently, there are a variety of anti-cancer drugs available in the first-line treatment of advanced NSCLC, such as cytotoxic agents, targeted agents, or ICIs. ICIs have transformed the paradigm of treatment for advanced NSCLC without EGFR, ALK, or ROS1 aberrations. However, randomized trials investigating the efficacy of ICIs as monotherapy or in combination with chemotherapy or other targeted agents are lacking for advanced NSCLC with high PD-L1 expression. Thus, there is still a need to optimize first-line treatment options for patients with advanced NSCLC highly expressing PD-L1. In the absences of head-to-head trials, a Bayesian network meta-analysis (NMA) can allow us to combine both direct and indirect evidence and compare several therapeutic regimens using a common comparator in the individual trials. To give an overview of the current status of immunotherapy in advanced NSCSC and suggest optimal frontline treatments for patients with high PD-L1 expression (at least $50 \%$ of tumor cells), we performed a systematic literature review and NMA of randomized clinical trials.

\section{Materials and Methods}

\subsection{Searching strategy}

We searched the Cochrane Central Register of Controlled Trials, PubMed, and EMBASE for articles that included the following search terms in their titles, abstracts, or keyword lists: 'metastatic or advanced', 'non-small cell', 'lung', 'malignant or neoplasm or cancer or carcinoma', 'treatment', 'chemotherapy', 'immune checkpoint inhibitor or immunotherapy' and 'randomized or randomised'. All eligible studies were retrieved, and their bibliographies were checked for other relevant publications. We also scanned the reference lists of relevant articles and reviews. In addition, we used the 'related articles' features in PubMed to identify other potentially eligible articles. In case of duplicate publications, the recent paper was selected. Two independent reviewers examined the titles, abstracts, and full articles to determine the eligibility of the identified trials. Disagreements were resolved through consensus or consultation with a third reviewer.

\subsection{Selection criteria}

All potentially eligible studies identified using the search strategy were screened. Clinical trials that met the following criteria were reviewed for the NMA: (i) prospective randomized phase II or III trials for advanced NSCLC; (ii) trials comparing treatment regimens in the first-line setting; (iii) trials reporting the efficacy according to the level of PDL1 expression or studies conducted for advanced NSCLC with greater than or equal to $50 \%$ PD-L1 expression.

\subsection{Definition of high PD-L1 expression}

High PD-L1 expression is defined as a tumor proportion score (TPS) $\geq 50 \%$ or as either $\geq 50 \%$ of tumor cells (TC; TC3) or $\geq 10 \%$ of tumor-infiltrating immune cells (IC; IC3) [4]. 


\subsection{Data extraction}

Two independent reviewers extracted the complete data from each included trial using a standardized data extraction form. Extracted data included the details of the trials (year of publication, treatments, number of patients, and histology) and outcome measures (PFS and OS). The risk of bias for each trial was assessed by the Cochrane risk of bias method. Discrepancies in data extraction were resolved through discussion.

\subsection{Data analysis}

The primary outcomes intended to analyze were OS and PFS, which were reported as a hazard ratio (HR) and its 95\% confidence intervals (CIs). A Bayesian NMA was conducted to evaluate the treatment effects by direct pairwise and indirect comparisons and to provide a hierarchical ranking for the treatments without direct comparisons between them. Considering the heterogeneity between included trials, a random-effects model was incorporated and an informative prior of a log-normal $(-3.95,1.342)$ distribution was set in the Bayesian framework [37].

The posterior distributions were obtained using Markov-chain Monte Carlo process with 5,000 burn-ins and 50,000 iterations of four chains, which were thinned after every 10th simulation to reduce autocorrelation [38]. The convergence of the model was assessed by evaluating the trace plots and Gelman-Rubin diagnostics with a cut-off value of 1.05 [39]. The effect sizes of the Bayesian NMA were presented as the HR with $95 \%$ credible intervals (CrIs). To provide the rankings of each treatment, the surface under the cumulative ranking curve (SUCRA) values were calculated. The higher the SUCRA value, the higher the likelihood that a treatment would be in the top rank [40].

The statistical heterogeneity was evaluated using the statistic inconsistency index $\left(I^{2}\right)$. $I^{2}$ values of $<25 \%, 25-50 \%$, and $>50 \%$ indicate low, moderate, and high heterogeneity across randomized controlled trials, respectively. To discover the consistency, the node splitting analysis was performed to check the differences between direct and indirect comparisons among closed loops of each network. Egger's test and Begg's test were applied to determine publication bias across included trials where $\mathrm{P}$ values of $<0.05$ indicated publication bias. The statistical software $\mathrm{R}$ ( $\mathrm{R}$ version 4.0.5, https://www.r-project.org/) and the $\mathrm{R}$ package GeMTC (version 1.0-1) were used to perform the NMA.

\section{Results}

\subsection{Literature search and study characteristics}

A total of 4,225 studies were retrieved during the literature search, from which 2,127 duplicates were removed. Of the remaining studies, 1,923 were excluded by inspecting titles and abstracts and then the full texts of 175 articles were reviewed. Finally, 22 randomized phase II or III trials were selected for the Bayesian NMA [13,15-17,19-34,41-43]. A flow diagram illustrating the process of literature selection is shown in Figure 1.

\subsection{Characteristics of the included studies}

The detailed characteristics of the included trials are summarized in Table 1. From 22 eligible studies, a total of 5,237 NSCLC patients with high PD-L1 expression were included in this NMA. The patients were received one of the following 18 treatment strategies: pembrolizumab, pembrolizumab plus doublet, atezolizumab plus doublet, pembrolizumab plus ipilimumab, atezolizumab plus bevacizumab plus doublet, bevacizumab plus doublet, nivolumab, nivolumab plus ipilimumab, nivolumab plus ipilimumab plus doublet, nivolumab plus bevacizumab plus doublet, durvalumab, durvalumab plus tremelimumab, durvalumab plus tremelimumab plus doublet, camrelizumab plus doublet, tislelizumab plus doublet, sintilimab plus doublet, cemiplimab, and doublet chemotherapy. 

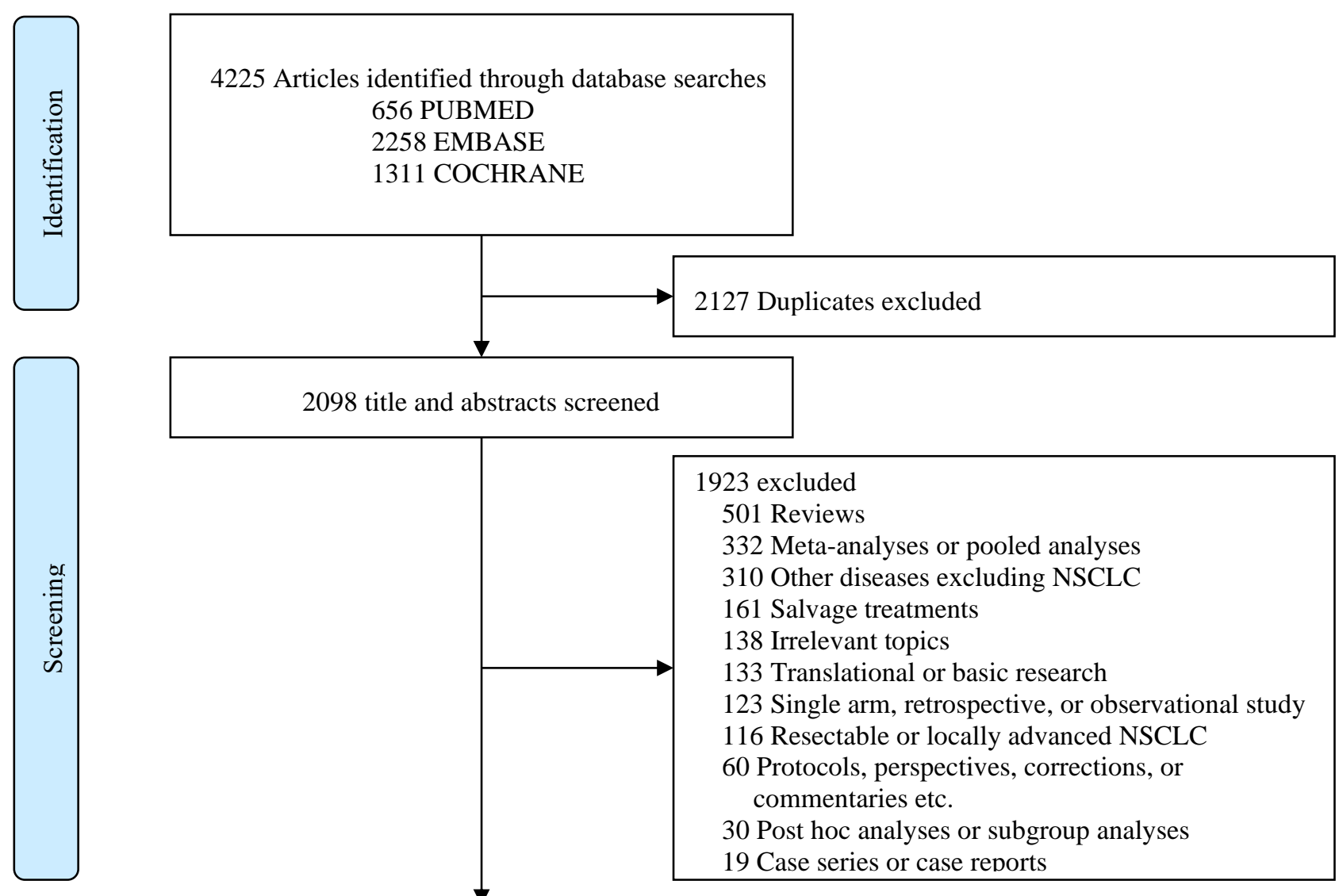

175 Full-text articles assessed for eligibility

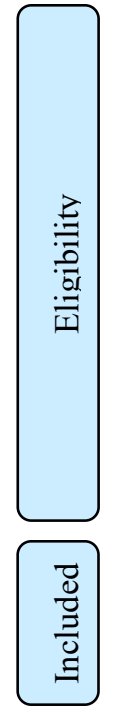

153 excluded

95 Insufficient data

26 Duplication

11 Post hoc analyses or subgroup analyses

8 Inappropriate comparative arms

5 Non-randomised studies

4 Meta-analyses or pooled analyses

2 Irrelevant topics

2 Retrospective or observational studies

1 Review

Figure 1 Preferred Reporting Items for Systematic Reviews and Meta-analyses (PRISMA) flow diagram showing the selection process of studies included in Bayesian network meta-analysis. 
Table 1. Main characteristics of the 22 studies included in the Bayesian network meta-analysis

\begin{tabular}{|c|c|c|c|c|c|c|c|}
\hline Study [ref] & $\begin{array}{l}\text { Sample } \\
\text { Size }\end{array}$ & Histology & "PD-L1 status: n(\%) & Intervention Arm & Control Arm & OS & PFS \\
\hline $\begin{array}{c}\text { KEYNOTE-024 } \\
{[13]}\end{array}$ & 305 & NSCLC & $\geq 50 \%: 305(100)$ & Pembrolizumab & $\begin{array}{l}\text { Doublet chemo- } \\
\text { therapy }\end{array}$ & $0.62(0.48-0.81)$ & $0.50(0.39-0.65)$ \\
\hline $\begin{array}{c}\text { KEYNOTE-042 } \\
{[15]}\end{array}$ & 1274 & NSCLC & $\geq 50 \%: 599(47)$ & Pembrolizumab & $\begin{array}{l}\text { Doublet chemo- } \\
\text { therapy }\end{array}$ & $0.68(0.57-0.82)$ & $0.85(0.72-1.02)$ \\
\hline $\begin{array}{c}\text { KEYNOTE-189 } \\
{[29]}\end{array}$ & 616 & Nonsquamous & $\geq 50 \%: 202(33)$ & $\begin{array}{c}\text { Pembrolizumab + Doublet } \\
\text { chemotherapy }\end{array}$ & $\begin{array}{l}\text { Doublet chemo- } \\
\text { therapy }\end{array}$ & $0.59(0.40-0.86)$ & $0.35(0.25-0.49)$ \\
\hline $\begin{array}{c}\text { KEYNOTE-407 } \\
{[16]} \\
\end{array}$ & 559 & Squamous & $\geq 50 \%: 146(26)$ & $\begin{array}{c}\text { Pembrolizumab + Doublet } \\
\text { chemotherapy }\end{array}$ & $\begin{array}{l}\text { Doublet chemo- } \\
\text { therapy }\end{array}$ & $0.79(0.52-1.21)$ & $0.37(0.24-0.58)$ \\
\hline $\begin{array}{c}\text { KEYNOTE-598 } \\
{[43]} \\
\end{array}$ & 568 & NSCLC & $\geq 50 \%: 568(100)$ & $\begin{array}{c}\text { Pembrolizumab + ipili- } \\
\text { mumab }\end{array}$ & Pembrolizumab & $1.08(0.85-1.37)$ & $1.06(0.86-1.30)$ \\
\hline $\begin{array}{c}\text { IMpower110 } \\
{[21]}\end{array}$ & 554 & NSCLC & TC3 or IC3: 205 (37) & $\begin{array}{l}\text { Atezolizumab + Doublet } \\
\text { chemotherapy }\end{array}$ & $\begin{array}{l}\text { Doublet chemo- } \\
\text { therapy }\end{array}$ & $0.59(0.40-0.89)$ & $0.63(0.45-0.88)$ \\
\hline $\begin{array}{c}\text { IMpower130 } \\
{[19]}\end{array}$ & 724 & Nonsquamous & TC3 or IC3: 134 (19) & $\begin{array}{l}\text { Atezolizumab + Doublet } \\
\text { chemotherapy }\end{array}$ & $\begin{array}{l}\text { Doublet chemo- } \\
\text { therapy }\end{array}$ & $0.84(0.51-1.39)$ & $0.51(0.34-0.77)$ \\
\hline $\begin{array}{c}\text { IMpower131 } \\
{[20]}\end{array}$ & 1021 & Squamous & TC3 or IC3: 154 (15) & $\begin{array}{c}\text { Atezolizumab + Doublet } \\
\text { chemotherapy }\end{array}$ & $\begin{array}{l}\text { Doublet chemo- } \\
\text { therapy }\end{array}$ & $0.48(0.29-0.81)$ & $0.41(0.25-0.68)$ \\
\hline $\begin{array}{c}\text { IMpower132 } \\
{[22]}\end{array}$ & 578 & Nonsquamous & TC3 or IC3: 45 (8) & $\begin{array}{c}\text { Atezolizumab + Doublet } \\
\text { chemotherapy }\end{array}$ & $\begin{array}{l}\text { Doublet chemo- } \\
\text { therapy }\end{array}$ & $0.73(0.31-1.73)$ & $0.46(0.22-0.96)$ \\
\hline $\begin{array}{c}\text { IMpower150 } \\
{[30]}\end{array}$ & 1047 & Nonsquamous & $\geq 50 \%: 206(24)$ & $\begin{array}{l}\text { 1. Atezolizumab + Bevaci- } \\
\text { zumab + Doublet chemo- } \\
\text { therapy } \\
\text { 2. Atezolizumab + Doublet } \\
\text { chemotherapy }\end{array}$ & $\begin{array}{l}\text { Bevacizumab + } \\
\text { Doublet chemo- } \\
\text { therapy }\end{array}$ & $0.76(0.49-1.17)$ & $0.62(0.3-0.89)$ \\
\hline $\begin{array}{c}\text { CheckMate } 026 \\
\text { [17] } \\
\end{array}$ & 541 & NSCLC & $\geq 50 \%: 214(40)$ & Nivolumab & $\begin{array}{l}\text { Doublet chemo- } \\
\text { therapy }\end{array}$ & $0.90(0.63-1.29)$ & $1.07(0.77-1.49)$ \\
\hline $\begin{array}{c}\text { CheckMate 9LA } \\
\text { [26] }\end{array}$ & 719 & NSCLC & $\geq 50 \%: 174(26)$ & $\begin{array}{c}\text { Nivolumab + Ipilimumab + } \\
\text { Doublet chemotherapy }\end{array}$ & $\begin{array}{l}\text { Doublet chemo- } \\
\text { therapy }\end{array}$ & $0.66(0.44-0.99)$ & $0.61(0.42-0.89)$ \\
\hline $\begin{array}{c}\text { CheckMate } 227 \\
{[25,41]}\end{array}$ & 1189 & NSCLC & $\geq 50 \%: 611(51)$ & $\begin{array}{c}\text { 1. Nivolumab + Ipili- } \\
\text { mumab } \\
\text { 2. Nivolumab }\end{array}$ & $\begin{array}{l}\text { Doublet chemo- } \\
\text { therapy }\end{array}$ & $0.70(0.55-0.90)$ & - \\
\hline \multirow[t]{2}{*}{$\begin{array}{l}\text { MYSTIC } \\
{[27]}\end{array}$} & \multirow[t]{2}{*}{1118} & \multirow[t]{2}{*}{ NSCLC } & \multirow[t]{2}{*}{$\geq 50 \%: 333(30)$} & $\begin{array}{l}\text { 1. Durvalumab + } \\
\text { Tremelimumab }\end{array}$ & \multirow{2}{*}{$\begin{array}{l}\text { Doublet chemo- } \\
\text { therapy }\end{array}$} & $0.77(0.56-1.07)$ & $1.05(0.72-1.53)$ \\
\hline & & & & 2. Durvalumab & & $0.76(0.55-1.04)$ & $0.87(0.59-1.29)$ \\
\hline $\begin{array}{c}\text { CameL } \\
{[23]}\end{array}$ & 412 & Nonsquamous & $\geq 50 \%: 50(24)$ & $\begin{array}{c}\text { Camrelizumab + Doublet } \\
\text { chemotherapy }\end{array}$ & $\begin{array}{l}\text { Doublet chemo- } \\
\text { therapy }\end{array}$ & 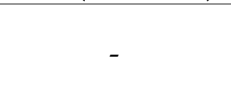 & $0.39(0.14-0.99)$ \\
\hline
\end{tabular}




\begin{tabular}{|c|c|c|c|c|c|c|c|}
\hline $\begin{array}{c}\text { CCTG BR } 34 \\
{[42]}\end{array}$ & 301 & NSCLC & $\geq 50 \%: 57(19)$ & $\begin{array}{c}\text { Durvalumab + } \\
\text { Tremelimumab + Doublet } \\
\text { chemotherapy }\end{array}$ & $\begin{array}{l}\text { Durvalumab + } \\
\text { Tremelimumab }\end{array}$ & $0.56(0.27-1.17)$ & $0.62(0.32-1.19)$ \\
\hline $\begin{array}{l}\text { RATIONALE } 304 \\
\text { [33] }\end{array}$ & 334 & Nonsquamous & $\geq 50 \%: 110(33)$ & $\begin{array}{c}\text { Tislelizumab + Doublet } \\
\text { chemotherapy }\end{array}$ & $\begin{array}{l}\text { Doublet chemo- } \\
\text { therapy }\end{array}$ & - & $\begin{array}{l}0.308(0.167- \\
0.567)\end{array}$ \\
\hline $\begin{array}{c}\text { RATIONALE } 307 \\
\text { [32] }\end{array}$ & 360 & Squamous & $\geq 50 \%: 125(35$ & $\begin{array}{l}\text { Tislelizumab + Doublet } \\
\text { chemotherapy }\end{array}$ & $\begin{array}{l}\text { Doublet chemo- } \\
\text { therapy }\end{array}$ & - & $0.46(0.31-0.70)$ \\
\hline $\begin{array}{c}\text { ORIENT-11 } \\
{[31]}\end{array}$ & 397 & Nonsquamous & $\geq 50 \%: 168(42)$ & $\begin{array}{c}\text { Sintilimab + Doublet chem- } \\
\text { otherapy }\end{array}$ & $\begin{array}{l}\text { Doublet chemo- } \\
\text { therapy }\end{array}$ & - & $\begin{array}{l}0.310(0.197- \\
0.489)\end{array}$ \\
\hline $\begin{array}{c}\text { ORIENT-12 } \\
{[34]}\end{array}$ & 357 & Squamous & $\geq 50 \%: 121(34)$ & $\begin{array}{c}\text { Sintilimab + Doublet chem- } \\
\text { otherapy }\end{array}$ & $\begin{array}{l}\text { Doublet chemo- } \\
\text { therapy }\end{array}$ & - & $\begin{array}{l}0.458(0.302- \\
0.695)\end{array}$ \\
\hline $\begin{array}{c}\text { EMPOWER-Lung } \\
\mathbf{1} \\
{[24]}\end{array}$ & 710 & NSCLC & $\geq 50 \%: 563(79)$ & Cemiplimab & $\begin{array}{l}\text { Doublet chemo- } \\
\text { therapy }\end{array}$ & $0.57(0.42-0.77)$ & $0.54(0.43-0.68)$ \\
\hline $\begin{array}{l}\text { TASUKI-52 } \\
{[28]}\end{array}$ & 550 & Nonsquamous & $\geq 50 \%: 147(27)$ & $\begin{array}{l}\text { Nivolumab + Bevacizumab } \\
\text { + Doublet chemotherapy }\end{array}$ & $\begin{array}{l}\text { Bevacizumab + } \\
\text { Doublet chemo- } \\
\text { therapy }\end{array}$ & - & $0.55(0.36-0.83)$ \\
\hline \multicolumn{8}{|c|}{$\begin{array}{l}\text { Abbreviations: ref, reference; Beva: bevacizumab; ICI: immune checkpoint inhibitor. } \\
\text { "This network meta-analysis focused on patients with PD-L1 } 250 \% \text { or TC3/IC3. }\end{array}$} \\
\hline
\end{tabular}

Abbreviations: ref, reference; Beva: bevacizumab; ICI: immune checkpoint inhibitor.

*This network meta-analysis focused on patients with PD-L1 $\geq 50 \%$ or TC3/IC3.

\author{
The
}

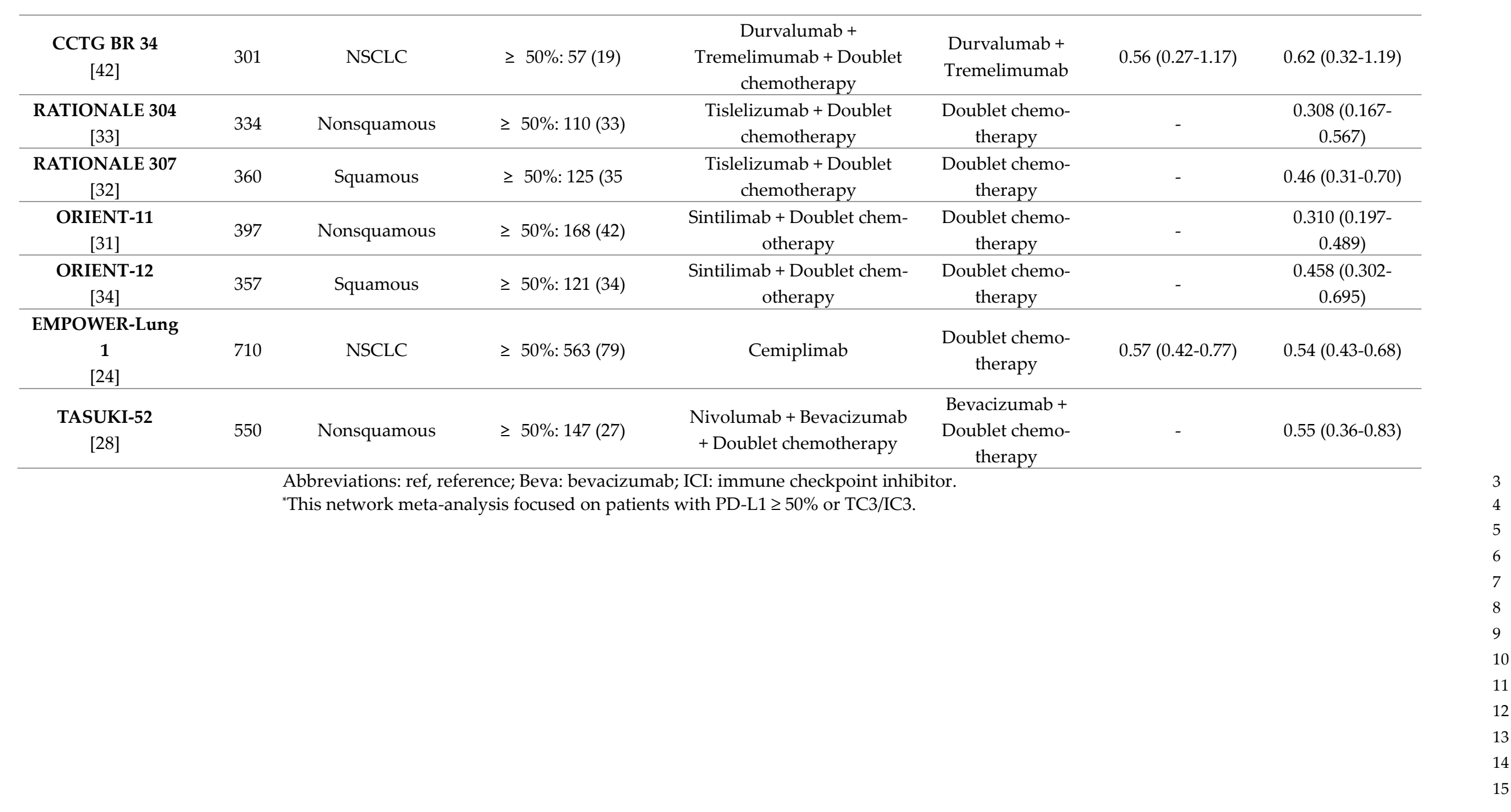

.




\subsection{Network analysis diagrams}

In this NMA, the treatment regimens were assigned into one of the following nodes: ICI monotherapy, ICI plus doublet, double ICIs, double ICIs plus doublet, ICI plus bevacizumab plus doublet, or doublet chemotherapy. The network analysis diagrams for OS and PFS are shown in Figure 2.

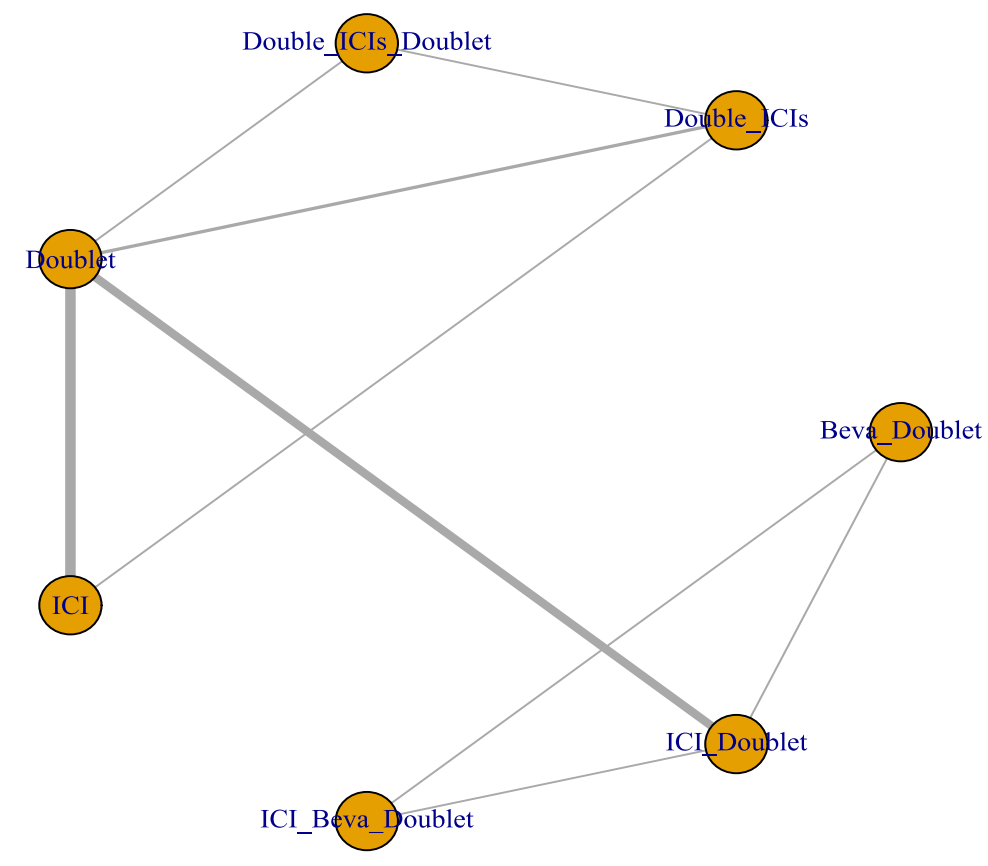

Figure 2. The network analysis diagram.

Abbreviations: Beva: bevacizumab; ICI: immune checkpoint inhibitor; Doublet, doublet chemotherapy

\subsection{Risk of bias assessment}

Since all studies were well-designed randomized controlled trials, the risk of bias was low in general across the studies (Figure S1). Although there was no information about the methods of randomization and allocation concealment in several trials, selection and attrition bias seemed to be minimal. However, the studies with open-labeled design $(63.6 \%)$ were scored as having a high risk of bias in terms of blinding of participants and personnel. Because almost all studies were analyzed based on the intention-to-treat population and reported sufficient endpoints, a low risk of bias was observed with respect to the incomplete outcome data and selective reporting.

\subsection{Progression-free survival}

Seven network nodes covering 17 treatment regimens were included in the Bayesian NMA for PFS. The Gelman-Rubin diagnostic statistic value of 1.006 supported the model convergence, and the statistical heterogeneity was low across the trials $\left(I^{2}=14 \%\right)$ by fitting the random-effects model with appropriate informative prior distributions. Egger's and Begg's tests with a funnel plot indicated that there was no significant publication bias (Egger's P=0.300, Begg's P=0.082). The node-splitting model indicated that there were no significant differences between direct and indirect comparisons, suggesting no inconsistency in the network.

The forest plot revealed that four network nodes had significant superiority to doublet chemotherapy (Figure 3). ICI plus doublet chemotherapy had a significantly better PFS over ICI monotherapy (HR=0.571, 95\% CrI: 0.454-0.709). The relative effects of all network node pairs on PFS are summarized in Table 2. Based on the SUCRA values, ICI plus bevacizumab plus doublet chemotherapy had the highest probability of being the most effective regimen $(98.1 \%)$, followed by ICI plus doublet chemotherapy $(82.9 \%)$. 


\begin{tabular}{|c|c|c|c|c|}
\hline Compared with Doublet chemotherapy & HR & $95 \% \mathrm{Crl}$ & & \\
\hline ICI_Doublet & $\begin{array}{l}0.285 \\
0.398\end{array}$ & $(0.337,0.473)$ & - & \\
\hline Beva_Doublet & 0.581 & $(0.325,1.067)$ & & 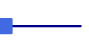 \\
\hline Double_ICls_Doublet & 0.595 & $(0.385,0.960)$ & & \\
\hline $\mathrm{ICl}-2-$ & 0.699 & $(0.591,0.810)$ & & - \\
\hline Double_ICls & 0.816 & $(0.627,1.426)$ & & $\longrightarrow$ \\
\hline
\end{tabular}

Figure 3. Network forest plot of treatment regimens compared with doublet chemotherapy for PFS

\subsection{Overall survival}

In this Bayesian NMA, 14 treatment regimens were available for OS analysis and assigned into seven network nodes. Model convergence was confirmed based on the Gelman-Rubin diagnostic statistic value of 1.009 and diagnostic plots. Statistical heterogeneity was found to be low across the included trials $\left(I^{2}=0 \%\right)$ after applying the randomeffects model with appropriate informative prior distributions. Significant publication bias was not observed when Egger's and Begg's tests with a funnel plot were performed (Egger's $\mathrm{P}=0.868$, Begg's $\mathrm{P}=0.371$ ). The node-splitting analysis revealed that there were no significant differences between the direct and indirect estimates, indicating no inconsistency in the network.

Except for bevacizumab plus doublet chemotherapy, all treatments demonstrated a significantly reduced risk of death compared with doublet chemotherapy (Figure 4). However, none of treatment regimens incorporating ICI showed significantly better OS than others in patients with NSCLC highly expressing PD-L1. Especially, ICI plus doublet chemotherapy failed to show a significant superiority over ICI monotherapy (HR $=0.978$, 95\% CrI: 0.771-1.259).

The relative effects of all network node pairs for OS are presented in Table 3. The ranking of each treatment strategy was estimated according to the SUCRA values. Double ICIs plus doublet chemotherapy had the highest SUCRA value $(79.1 \%)$, followed by ICI plus bevacizumab plus doublet (73.4\%). ICI doublet (64.9\%) and ICI $(61.8 \%)$ have a similar SUCRA value indicating that they are equally effective against NSCLC with high PD-L1 expression in terms of OS.

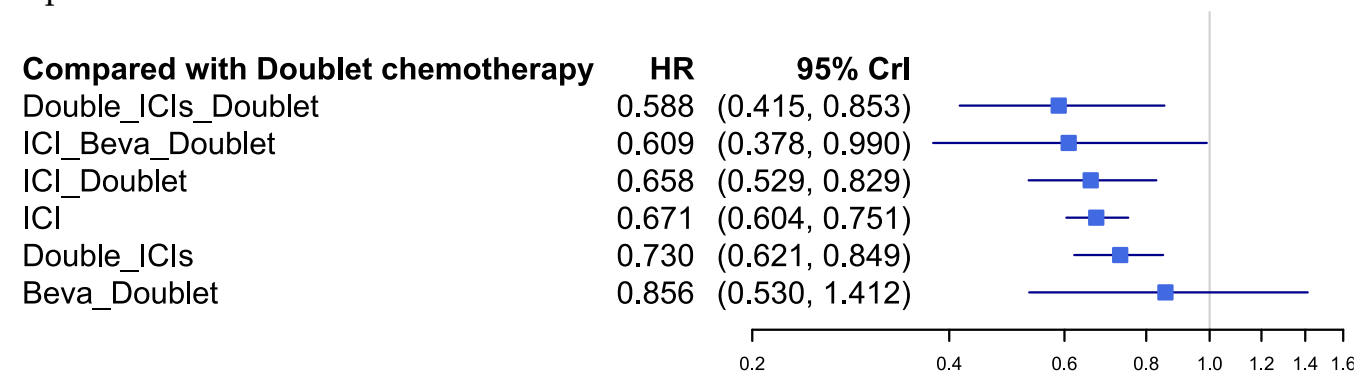

Figure 4. Network forest plot of each treatment strategy compared with doublet chemotherapy for OS. 
Table 2. The league table for the relative effects of all pairs of the network nodes and ranking for the probability of each network node to be the best for PFS based on the SUCRA values.

\begin{tabular}{|c|c|c|c|c|c|c|}
\hline & & & & & & $\begin{array}{c}\text { SUCRA } 98.1 \\
\text { ICI_Beva_Doublet }\end{array}$ \\
\hline & & & & & $\begin{array}{l}\text { SUCRA } 82.9 \\
\text { ICI_Doublet }\end{array}$ & $\begin{array}{c}0.714 \\
(0.423,1.203) \\
\end{array}$ \\
\hline & & & & $\begin{array}{c}\text { SUCRA } 55.7 \\
\text { Double_ICIs_Doublet }\end{array}$ & $\begin{array}{c}0.686 \\
(0.45,1.032) \\
\end{array}$ & $\begin{array}{c}0.489 \\
(0.249,0.949) \\
\end{array}$ \\
\hline & & & $\begin{array}{c}\text { SUCRA } 51.7 \\
\text { Beva_Doublet }\end{array}$ & $\begin{array}{c}0.977 \\
(0.492,2.002) \\
\end{array}$ & $\begin{array}{c}0.671 \\
(0.382,1.19) \\
\end{array}$ & $\begin{array}{c}0.478 \\
(0.339,0.678) \\
\end{array}$ \\
\hline & & $\begin{array}{c}\text { SUCRA } 39.7 \\
\text { ICI } \\
\end{array}$ & $\begin{array}{c}0.850 \\
(0.462,1.546) \\
\end{array}$ & $\begin{array}{c}0.832 \\
(0.561,1.235) \\
\end{array}$ & $\begin{array}{c}0.571 \\
(0.454,0.709) \\
\end{array}$ & $\begin{array}{c}0.407 \\
(0.229,0.716) \\
\end{array}$ \\
\hline & $\begin{array}{l}\text { SUCRA } 20.2 \\
\text { Double_ICIs }\end{array}$ & $\begin{array}{c}0.856 \\
(0.665,1.073) \\
\end{array}$ & $\begin{array}{c}0.725 \\
(0.379,1.367) \\
\end{array}$ & $\begin{array}{c}0.712 \\
(0.465,1.059) \\
\end{array}$ & $\begin{array}{c}0.487 \\
(0.352,0.652) \\
\end{array}$ & $\begin{array}{c}0.347 \\
(0.188,0.632) \\
\end{array}$ \\
\hline $\begin{array}{c}\text { SUCRA } 1.8 \\
\text { Doublet }\end{array}$ & $\begin{array}{c}0.816 \\
(0.641,1.078)\end{array}$ & $\begin{array}{c}0.699 \\
(0.605,0.815)\end{array}$ & $\begin{array}{c}0.595 \\
(0.327,1.068)\end{array}$ & $\begin{array}{c}0.581 \\
(0.399,0.854)\end{array}$ & $\begin{array}{c}0.398 \\
(0.336,0.473)\end{array}$ & $\begin{array}{c}0.285 \\
(0.163,0.493)\end{array}$ \\
\hline
\end{tabular}

Abbreviations: Beva: bevacizumab; ICI: immune checkpoint inhibitor; doublet, doublet chemotherapy. Bold indicates statistically significant differences. 


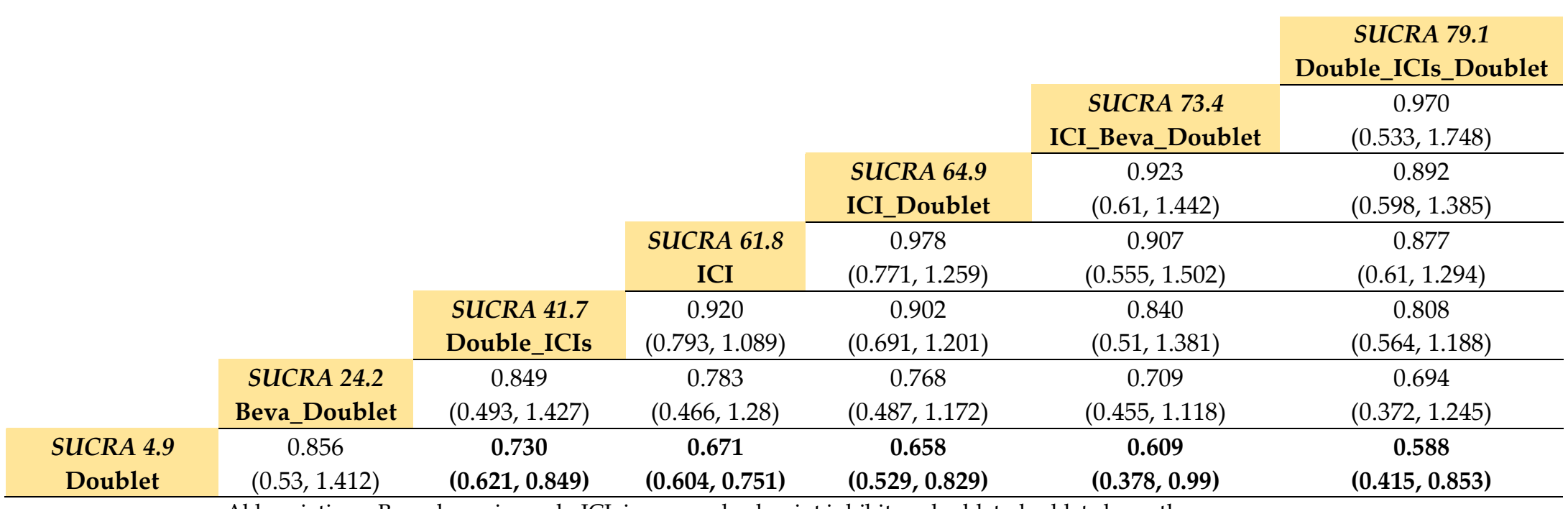

Abbreviations: Beva: bevacizumab; ICI: immune checkpoint inhibitor, doublet, doublet chemotherapy

Bold indicates statistically significant differences. 


\section{Discussion}

131

For this Bayesian NMA, we analyzed survival data of a total of 5,237 patients from 22 randomized phase II or III trials in the first-line treatment setting for advanced NSCLC [13,15-17,19-34,41-43]. Our study used the most recent clinical outcomes and the most appropriate statistical methods for ICI immunotherapy-specific considerations. The analysis focused on patients whose tumors had high PD-L1 expression $(\geq 50 \%)$. Based on the SUCRA values, ICI plus bevacizumab plus chemotherapy or ICI plus chemotherapy is likely to be the best options in terms of OS.

Compared to patients with no PD-L1 expression by IHC, those showing PD-L1 expression on tumor cells and/or tumor-infiltrating immune cells tend to enjoy better outcomes from ICIs, as monotherapy or as part of combination therapy [7-14]. In term of PFS or OS, the greatest benefit of ICIs has been observed in the subgroup of patients with greater than or equal to $50 \%$ PD-L1 expression $[15,16,19,33]$. Thus, PD-L1 may serve as an effective tumor biomarker for most ICIs in advanced NSCLC, with increasing PD-L1 expression correlating with even better outcomes.

An increasing number of studies have suggested that there may be the synergistic anti-tumor effects between ICIs and chemotherapy. Cytotoxic agents may exhibit positive immuno-modulatory effects by releasing high level of tumor antigens and changing tumor micro-environment [44,45]. Accordingly, the combination of ICI and chemotherapy may reveal greater efficacy than chemotherapy alone, particularly in patients with lower PD-L1 expression levels. Actually, many randomized clinical trials have suggested that combining an anti-PD-1 mAb (pembrolizumab, camrelizumab, tislelizumab, sintilimab) or anti-PD-L1 inhibitor (atezolizumab) with platinum-doublet chemotherapy could significantly improve PFS or OS compared with chemotherapy alone in patients with advanced squamous and nonsquamous NSCLC, irrespective of the level of PD-L1 expression $[16,18,19,23,32,34,41]$. Recently, camrelizumab, a humanized mAb against PD-1, in combination with pemetrexed plus carboplatin achieved a significant improvement of PFS (median 11.3 vs 8.3 mo, HR=0.60, 95\% CI: 0.45-0.79) compared with chemotherapy alone in Chinese patients with advanced nonsquamous NSCLC [23]. Sintilimab is an IgG4 anti-PD-1 mAb that blocks the interaction of PD-1 and its ligands with high affinity [46]. In the phase III ORIENT-11 study, the addition of sintilimab to chemotherapy (pemetrexed plus platinum) led to significantly longer OS (median not reached vs. 16.8 mo, HR=0.60, 95\% CI: 0.45-0.79) for advanced nonsquamous NSCLC [31]. In addition, the ORIENT-12 study found that adding sintilimab to gemcitabine plus platinum significantly prolonged PFS (HR=0.536, 95\% CI: 0.422-0.681) compared with chemotherapy alone as first-line treatment for advanced squamous NSCLC [34]. Tislelizumab is a mAb with high binding affinity to PD-1 receptor which was specifically engineered to minimize Fc $\gamma$ receptor binding on macrophages. In the phase III randomized clinical trial (RATIONALE 307), adding tislelizumab to chemotherapy (paclitaxel or nab-paclitaxel plus carboplatin) was associated with significantly improved ORR and PFS in Chinese patients with treatment-naive advanced squamous NSCLC, regardless of PD-L1 expression [32].

Besides ICIs targeting PD-1/PD-L1, cytotoxic T-lymphocyte-associated protein-4 (CTLA-4) checkpoint inhibitors also enhance T-cell activity against tumors with different complementary mechanisms. The first phase III study of dual immunotherapy, CheckMate 227, investigated the efficacy of nivolumab plus ipilimumab compared with platinum-based chemotherapy as frontline treatment of advanced NSCLC without EGFR or $A L K$ mutations [25]. The updated results of the CheckMate 227 part 1 recently reported [41]. With a median follow-up 54.8 months, OS remained longer with nivolumab plus ipilimumab versus chemotherapy not only in patients with PD-L1 greater than or equal to $1 \%$ (HR=0.76, 95\% CI: 0.65-0.90) but also in patients with PD-L1 less than $1 \%$ (HR=0.64, 95\% CI: 0.51-0.81). In the CheckMate 9LA trial, first-line nivolumab plus ipilimumab combined with two cycles of chemotherapy improved OS versus chemotherapy alone (median OS 15.6 vs. 10.9 mo, HR=0.66, 95\% CI: $0.55-0.80$ ) in patients with advanced NSCLC [26]. In the phase III MYSTIC trial, however, dual immunotherapy with durvalumab and tremelimumab failed to improve PFS (median 3.9 vs. 5.4 mo, HR=1.05, 99.5\% CI: 0.722- 
1.534) or OS (median 11.9 vs. 12.9 mo, $\mathrm{HR}=0.85,98.77 \% \mathrm{CI}: 0.611-1.173$ ) compared with chemotherapy in advanced NSCLC with PD-L1 $\geq 25 \%$ [27]. In addition, the addition of chemotherapy to durvalumab plus tremelimumab in the first-line treatment of stage IV NSCLC did not improve survival compared to durvalumab plus tremelimumab alone in the randomized phase II trial (CCTR BR 34 study) [42]. Based on the results from the CheckMate 227 and CheckMate 9LA, nivolumab plus ipilimumab or nivolumab plus ipilimumab in combination with two cycles of chemotherapy might be new options for the frontline treatment of advanced NSCLC. However, given the increased cost and adverse effects of dual immunotherapy with or without chemotherapy, it seems to be necessary to explore the adequate population for these regimens.

For patients with advanced NSCLC expressing PD-L1 of at least $50 \%$, the results from several randomized studies indicate that ICI monotherapy is superior to chemotherapy in terms of both survival benefits and toxicity profile [14,24]. In the KEYNOTE-024 study, pembrolizumab provided meaningful survival benefits in both PFS (median 7.7 vs. 5.5 mo, $\mathrm{HR}=0.50,95 \%$ CI: 0.39-0.65) and OS (median 26.3 vs. 13.4 mo, HR=0.62, 95\% CI: 0.480.81 ) versus chemotherapy as first-line therapy for metastatic NSCLC with PD-L1 tumor proportion score greater than 50\% [13]. In the EMPOWER-Lung 1 study, cemiplimab, a fully human, hinge-stabilized, immunoglobulin G4, anti-PD-1 mAb, also significantly improved PFS (median 8.2 vs. 5.7 mo, HR=0.54, 95\% CI: 0.43-0.68) and OS (median not reached vs. $14.2 \mathrm{mo}, \mathrm{HR}=0.57,95 \% \mathrm{CI}$ : 0.42-0.77), compared with chemotherapy in patients with advanced NSCLC expressing PD-L1 of at least 50\% [24]. The Impower150 study was the first phase III trial to evaluate ICI (atezolizumab) in combination with an anti-angiogenic agent (bevacizumab) plus chemotherapy (paclitaxel and carboplatin) as frontline treatment of advanced nonsquamous NSCLC [17]. The results indicated that adding atezolizumab to chemotherapy plus bevacizumab significantly prolonged OS ( $\mathrm{HR}=0.80,95 \%$ CI: 0.67-0.95), compared with chemotherapy plus bevacizumab. Interestingly, the exploratory analyses found that median OS was longer in the atezolizumab plus chemotherapy arm versus the bevacizumab plus chemotherapy arm (23.3 vs. $11.2 \mathrm{mo}, \mathrm{HR}=0.59,95 \% \mathrm{CI}$ : 0.39-0.90) in the SP263-defined PD-L1-high subgroup (PD-L1 expressing tumor cells $\geq$ $50 \%$ ). In addition, the improvement of OS was also observed in the atezolizumab-bevacizumab-chemotherapy arm versus the bevacizumab-chemotherapy arm (median 21.8 vs. 11.2 mo, HR=0.62, 95\% CI: 0.40-0.94) in the PD-L1-high subgroup [17]. In the recent phase III KEYNOTE-598 study, however, adding ipilimumab to pembrolizumab failed to improve efficacy and was associated with greater toxicity than pembrolizumab monotherapy as first-line treatment for metastatic NSCLC with PD-L1 TPS $\geq 50 \%$ and no targetable EGFR or ALK aberrations [43].

As we reviewed above, available data indicate that the addition of ICIs to chemotherapy with or without an anti-angiogenic agent increases survival benefits in advanced NSCLC, regardless of PD-L1 expression proportions [16-19,23,32,34]. Except for the KEYNOTE-598 study [43], however, no randomized clinical trials comparing the efficacy of ICIs as monotherapy versus combination with other treatment options are now available for patients with advanced NSCLC highly expressing PD-L1. Because this subgroup may achieve greater survival benefits from anti-PD-1/PD-L1 mAbs than chemotherapy, sparing those patients the risk of increased toxicities with combination of other agents should be an important consideration. In this Bayesian NMA of 22 randomized phase II or III trials with a total of 5,237 patients, we indirectly compared survival outcomes of the seven treatment nodes (ICI monotherapy, ICI plus doublet chemotherapy, double ICIs with or without doublet chemotherapy, bevacizumab plus doublet chemotherapy with or without ICI, and doublet chemotherapy) as first-line treatment for advanced NSCLC with high PD-L1 expression. In terms of PFS, four network nodes (ICI monotherapy, ICI plus chemotherapy, and bevacizumab plus chemotherapy with or without ICI) showed significant superiority, compared with chemotherapy alone. Interestingly, ICI plus chemotherapy had a significantly better PFS over ICI monotherapy (HR=0.571, 95\% CrI: 0.454-0.709). When the ranking of each treatment was estimated according to SUCRA values, ICI plus bevacizumab plus chemotherapy had the highest probability of being the most effective 
regimen (98.1\%), followed by ICI plus chemotherapy (82.9\%). In terms of OS, all treatment regimens except for bevacizumab plus chemotherapy demonstrated longer survival compared with chemotherapy alone. However, none of treatment regimens incorporating ICI showed significantly better OS than others. Especially, ICI plus chemotherapy failed to show a significant superiority over ICI monotherapy (HR $=0.978,95 \%$ CrI: 0.771-1.259), indicating ICI plus chemotherapy has no survival advantage compared with ICI monotherapy for patients with PD-L1 expression of at least $50 \%$. Based on the SUCRA values, dual immunotherapy plus chemotherapy had the highest value $(79.1 \%)$, followed by ICI plus bevacizumab plus chemotherapy (73.4\%). However, it should be considered that only one or two studies were included in these treatment nodes. Moreover, dual immunotherapy $(64.9 \%)$ and ICI monotherapy $(61.8 \%)$ have similar SUCRA values suggesting that they are equally effective in terms of OS against advanced NSCLC with high PD-L1 expression.

Several limitations of this study need to be mentioned. First, this NMA was performed using aggregated data of results from the eligible trials, not individual-patient data. Second, only one or two studies were included in two treatment nodes (double ICI plus doublet and ICI plus bevacizumab plus doublet), which could result in estimates with lower statistical power. Third, we did not stratified patients according to the histology (squamous or non-squamous) because of the limited number of available studies for each histology. Forth, we did not compare the toxicity profiles between treatment strategies in the current study because other network meta-analyses have demonstrated that ICI monotherapy had significantly lower odds of any adverse events than chemotherapy or combination of ICI and chemotherapy $[4,36]$. Finally, the IHC methods measuring PDL1 expression level were different among studies, which might cause patients to be misclassified.

In conclusion, we combined both direct and indirect evidence in this NMA of randomized trials to suggest frontline treatments for advanced NSCLC with high PD-L1 expression $(\geq 50 \%)$. The results indicated that treatment regimens combined with immunotherapy reveal better survival outcomes compared with chemotherapy alone. Based on the SUCRA values, ICI plus bevacizumab plus chemotherapy or ICI plus chemotherapy might to be the best options in terms of OS. However, there was no significant difference of survival outcomes among treatment regimens combined with immunotherapy. Moreover, ICI plus chemotherapy failed to reveal significant survival benefits over ICI monotherapy. In terms of both OS and safety, therefore, ICI monotherapy may also be reasonable as first-line treatment for advanced NSCLC with high PD-L1 expression and no targetable aberrations. Considering no prospective direct comparison is now available, however, the choice of treatment should be determined based on patient-specific factors after open discussion with the patient on the benefits, cost, and risks of each option. Randomized clinical trials are still warranted in order to identify the best therapeutic strategy for patients with advanced NSCLC highly expressing PD-L1.

Supplementary Materials: The following supporting information can be downloaded at: www.mdpi.com/xxx/s1, Figure S1: Graphic (A) and tabular representation (B) of risk of bias in all studies included. 
Random sequence generation (selection bias)

Allocation concealment (selection bias)

Blinding of participants and personnel (performance bias)

Blinding of outcome assessment (detection bias)

Incomplete outcome data (attrition bias)

Selective reporting (reporting bias)

Other bias

(A)
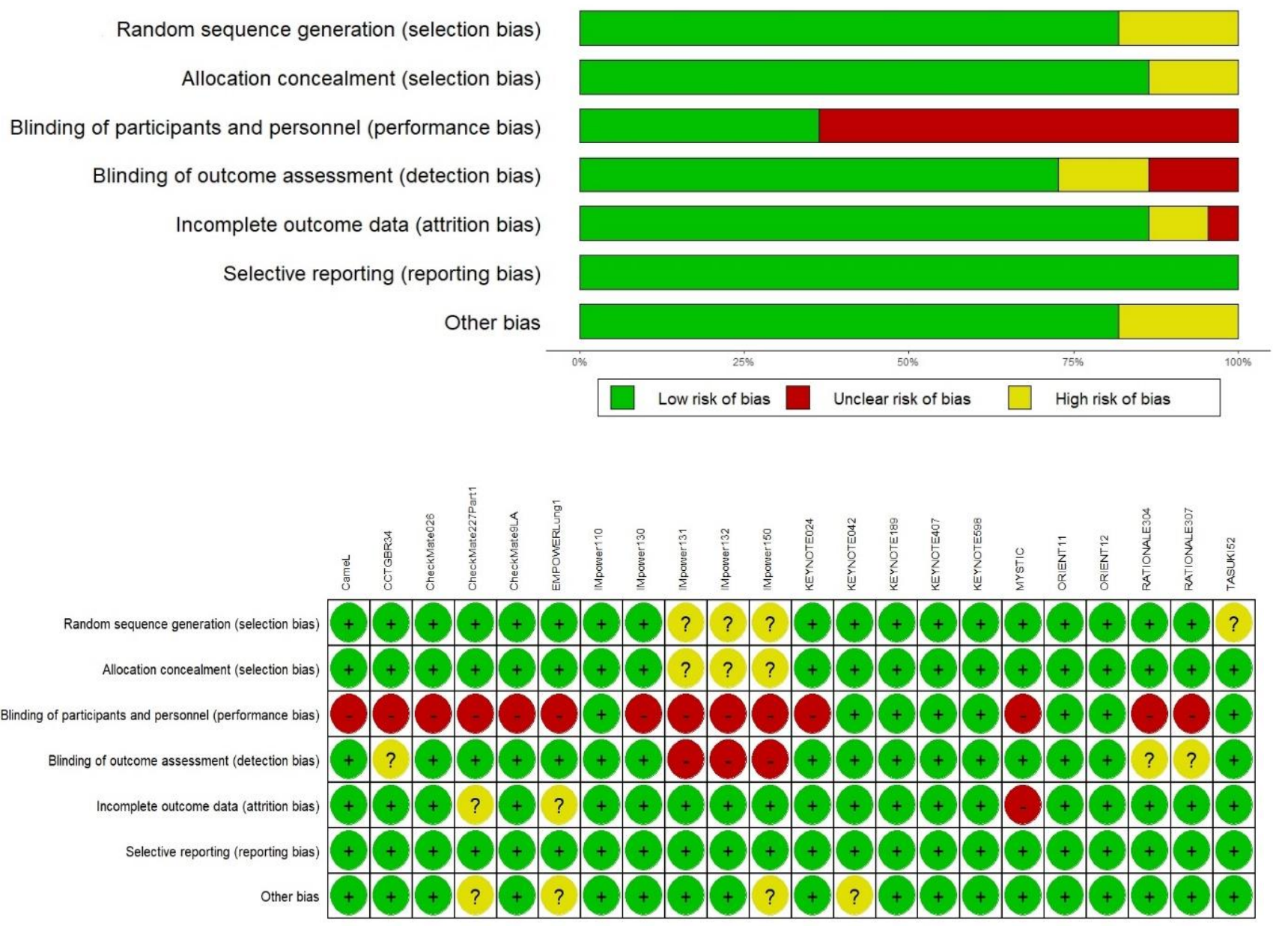

(B)

Author Contributions: Conceptualization, H.S.K. and J.H.K.; literature searching and data extraction, S.T.P. and S.Y.J.; methodology, H.S.K. and J.H.K.; software, H.S.K.; validation, H.S.K., S.T.P. and J.H.K.; formal statistical analysis, H.S.K. and S.T.P.; data curation, H.S.K.; writing-original draft preparation, J.H.K.; writing-review and editing, H.S.K., S.Y.J. and S.T.P.; supervision, H.S.K. and J.H.K.; funding acquisition, S.T.P. All authors have read and agreed to the published version of the manuscript.

Funding: This research was supported by a grant of the Korea Health Technology R\&D Project through the Korea Health Industry Development Institute (KHIDI), funded by the Ministry of Health \& Welfare, Republic of Korea (grant number: HR21C0198) \& Medical Technology Development Program of the National Research Foundation (NRF) \& funded by the Korean government, Ministry of Science and ICT (MSIT) (grant number: NRF- 2020R1G1A1005483)

Institutional Review Board Statement: Not applicable.

Informed Consent Statement: Not applicable.

Conflicts of Interest: The authors declare no conflict of interest. 
1. $\quad$ 1. Ferlay, J.; Colombet, M.; Soerjomataram, I.; Parkin, D.M.; Pineros, M.; Znaor, A.; Bray, F. Cancer statistics for the year 2020: An overview. Int J Cancer 2021, doi:10.1002/ijc.33588.

2. $\quad 2 . \quad$ Jung, K.W.; Won, Y.J.; Hong, S.; Kong, H.J.; Lee, E.S. Prediction of Cancer Incidence and Mortality in Korea, 2020. Cancer Res Treat 2020, 52, 351-358, doi:10.4143/crt.2020.203.

3. 3. Chen, Y.M. Immune checkpoint inhibitors for nonsmall cell lung cancer treatment. J Chin Med Assoc 2017, 80, 7-14, doi:10.1016/j.jcma.2016.08.005.

4. 4. Herbst, R.; Jassem, J.; Abogunrin, S.; James, D.; McCool, R.; Belleli, R.; Giaccone, G.; De Marinis, F. A Network MetaAnalysis of Cancer Immunotherapies Versus Chemotherapy for First-Line Treatment of Patients With Non-Small Cell Lung Cancer and High Programmed Death-Ligand 1 Expression. Front Oncol 2021, 11, 676732, doi:10.3389/fonc.2021.676732.

5. 5. Korman, A.J.; Peggs, K.S.; Allison, J.P. Checkpoint blockade in cancer immunotherapy. Adv Immunol 2006, 90, 297-339, doi:10.1016/S0065-2776(06)90008-X.

6. 6. Pardoll, D.M. The blockade of immune checkpoints in cancer immunotherapy. Nat Rev Cancer 2012, 12, 252-264, doi:10.1038/nrc3239.

7. $\quad$ 7. Herbst, R.S.; Baas, P.; Kim, D.W.; Felip, E.; Perez-Gracia, J.L.; Han, J.Y.; Molina, J.; Kim, J.H.; Arvis, C.D.; Ahn, M.J.; et al. Pembrolizumab versus docetaxel for previously treated, PD-L1-positive, advanced non-small-cell lung cancer (KEYNOTE010): a randomised controlled trial. Lancet 2016, 387, 1540-1550, doi:10.1016/S0140-6736(15)01281-7.

8. $\quad$ 8. Brahmer, J.; Reckamp, K.L.; Baas, P.; Crino, L.; Eberhardt, W.E.; Poddubskaya, E.; Antonia, S.; Pluzanski, A.; Vokes, E.E.; Holgado, E.; et al. Nivolumab versus Docetaxel in Advanced Squamous-Cell Non-Small-Cell Lung Cancer. N Engl J Med 2015, 373, 123-135, doi:10.1056/NEJMoa1504627.

9. 9. $\quad$ Borghaei, H.; Paz-Ares, L.; Horn, L.; Spigel, D.R.; Steins, M.; Ready, N.E.; Chow, L.Q.; Vokes, E.E.; Felip, E.; Holgado, E.; et al. Nivolumab versus Docetaxel in Advanced Nonsquamous Non-Small-Cell Lung Cancer. N Engl J Med 2015, 373, 16271639, doi:10.1056/NEJMoa1507643.

10. 10. Fehrenbacher, L.; Spira, A.; Ballinger, M.; Kowanetz, M.; Vansteenkiste, J.; Mazieres, J.; Park, K.; Smith, D.; Artal-Cortes, A.; Lewanski, C.; et al. Atezolizumab versus docetaxel for patients with previously treated non-small-cell lung cancer (POPLAR): a multicentre, open-label, phase 2 randomised controlled trial. Lancet 2016, 387, 1837-1846, doi:10.1016/S01406736(16)00587-0.

11. 11. Rittmeyer, A.; Barlesi, F.; Waterkamp, D.; Park, K.; Ciardiello, F.; von Pawel, J.; Gadgeel, S.M.; Hida, T.; Kowalski, D.M.; Dols, M.C.; et al. Atezolizumab versus docetaxel in patients with previously treated non-small-cell lung cancer (OAK): a phase 3, open-label, multicentre randomised controlled trial. Lancet 2017, 389, 255-265, doi:10.1016/S0140-6736(16)32517-X.

12. 12. Reck, M.; Rodriguez-Abreu, D.; Robinson, A.G.; Hui, R.; Csoszi, T.; Fulop, A.; Gottfried, M.; Peled, N.; Tafreshi, A.; Cuffe, S.; et al. Pembrolizumab versus Chemotherapy for PD-L1-Positive Non-Small-Cell Lung Cancer. N Engl J Med 2016, 375, 1823-1833, doi:10.1056/NEJMoa1606774.

13. 13. Reck, M.; Rodriguez-Abreu, D.; Robinson, A.G.; Hui, R.; Csoszi, T.; Fulop, A.; Gottfried, M.; Peled, N.; Tafreshi, A.; Cuffe, S.; et al. Updated Analysis of KEYNOTE-024: Pembrolizumab Versus Platinum-Based Chemotherapy for Advanced NonSmall-Cell Lung Cancer With PD-L1 Tumor Proportion Score of 50\% or Greater. J Clin Oncol 2019, 37, 537-546, doi:10.1200/JCO.18.00149.

14. 14. Gandhi, L.; Rodriguez-Abreu, D.; Gadgeel, S.; Esteban, E.; Felip, E.; De Angelis, F.; Domine, M.; Clingan, P.; Hochmair, M.J.; Powell, S.F.; et al. Pembrolizumab plus Chemotherapy in Metastatic Non-Small-Cell Lung Cancer. N Engl J Med 2018, 378 , 2078-2092, doi:10.1056/NEJMoa1801005.

15. 15. Mok, T.S.K.; Wu, Y.L.; Kudaba, I.; Kowalski, D.M.; Cho, B.C.; Turna, H.Z.; Castro, G., Jr.; Srimuninnimit, V.; Laktionov, K.K.; Bondarenko, I.; et al. Pembrolizumab versus chemotherapy for previously untreated, PD-L1-expressing, locally advanced or metastatic non-small-cell lung cancer (KEYNOTE-042): a randomised, open-label, controlled, phase 3 trial. Lancet 2019, 393, 1819-1830, doi:10.1016/S0140-6736(18)32409-7.

16. 16. Paz-Ares, L.; Vicente, D.; Tafreshi, A.; Robinson, A.; Soto Parra, H.; Mazieres, J.; Hermes, B.; Cicin, I.; Medgyasszay, B.; Rodriguez-Cid, J.; et al. A Randomized, Placebo-Controlled Trial of Pembrolizumab Plus Chemotherapy in Patients With Metastatic Squamous NSCLC: Protocol-Specified Final Analysis of KEYNOTE-407. J Thorac Oncol 2020, 15, 1657-1669, doi:10.1016/j.jtho.2020.06.015.

17. 17. Carbone, D.P.; Reck, M.; Paz-Ares, L.; Creelan, B.; Horn, L.; Steins, M.; Felip, E.; van den Heuvel, M.M.; Ciuleanu, T.E.; Badin, F.; et al. First-Line Nivolumab in Stage IV or Recurrent Non-Small-Cell Lung Cancer. N Engl J Med 2017, 376, 2415-2426, doi:10.1056/NEJMoa1613493.

18. 18. Awad, M.M.; Gadgeel, S.M.; Borghaei, H.; Patnaik, A.; Yang, J.C.; Powell, S.F.; Gentzler, R.D.; Martins, R.G.; Stevenson, J.P.; Altan, M.; et al. Long-Term Overall Survival From KEYNOTE-021 Cohort G: Pemetrexed and Carboplatin With or Without Pembrolizumab as First-Line Therapy for Advanced Nonsquamous NSCLC. J Thorac Oncol 2021, 16, 162-168, doi:10.1016/j.jtho.2020.09.015.

19. 19. West, H.; McCleod, M.; Hussein, M.; Morabito, A.; Rittmeyer, A.; Conter, H.J.; Kopp, H.G.; Daniel, D.; McCune, S.; Mekhail, T.; et al. Atezolizumab in combination with carboplatin plus nab-paclitaxel chemotherapy compared with chemotherapy alone as first-line treatment for metastatic non-squamous non-small-cell lung cancer (IMpower130): a multicentre, randomised, open-label, phase 3 trial. Lancet Oncol 2019, 20, 924-937, doi:10.1016/S1470-2045(19)30167-6.

20. 20. Jotte, R.; Cappuzzo, F.; Vynnychenko, I.; Stroyakovskiy, D.; Rodriguez-Abreu, D.; Hussein, M.; Soo, R.; Conter, H.J.; Kozuki, T.; Huang, K.C.; et al. Atezolizumab in Combination With Carboplatin and Nab-Paclitaxel in Advanced Squamous NSCLC (IMpower131): Results From a Randomized Phase III Trial. J Thorac Oncol 2020, 15, 1351-1360, doi:10.1016/j.jtho.2020.03.028. 
21. 21. Herbst, R.S.; Giaccone, G.; de Marinis, F.; Reinmuth, N.; Vergnenegre, A.; Barrios, C.H.; Morise, M.; Felip, E.; Andric, Z.; Geater, S.; et al. Atezolizumab for First-Line Treatment of PD-L1-Selected Patients with NSCLC. N Engl J Med 2020, 383, 13281339, doi:10.1056/NEJMoa1917346.

22. 22. Nishio, M.; Barlesi, F.; West, H.; Ball, S.; Bordoni, R.; Cobo, M.; Longeras, P.D.; Goldschmidt, J., Jr.; Novello, S.; Orlandi, F.; et al. Atezolizumab Plus Chemotherapy for First-Line Treatment of Nonsquamous NSCLC: Results From the Randomized Phase 3 IMpower132 Trial. J Thorac Oncol 2021, 16, 653-664, doi:10.1016/j.jtho.2020.11.025.

23. 23. Zhou, C.; Chen, G.; Huang, Y.; Zhou, J.; Lin, L.; Feng, J.; Wang, Z.; Shu, Y.; Shi, J.; Hu, Y.; et al. Camrelizumab plus carboplatin and pemetrexed versus chemotherapy alone in chemotherapy-naive patients with advanced non-squamous nonsmall-cell lung cancer (CameL): a randomised, open-label, multicentre, phase 3 trial. Lancet Respir Med 2021, 9, 305-314, doi:10.1016/S2213-2600(20)30365-9.

24. 24. Sezer, A.; Kilickap, S.; Gumus, M.; Bondarenko, I.; Ozguroglu, M.; Gogishvili, M.; Turk, H.M.; Cicin, I.; Bentsion, D.; Gladkov, O.; et al. Cemiplimab monotherapy for first-line treatment of advanced non-small-cell lung cancer with PD-L1 of at least 50\%: a multicentre, open-label, global, phase 3, randomised, controlled trial. Lancet 2021, 397, 592-604, doi:10.1016/S01406736(21)00228-2.

25. 25. Hellmann, M.D.; Paz-Ares, L.; Bernabe Caro, R.; Zurawski, B.; Kim, S.W.; Carcereny Costa, E.; Park, K.; Alexandru, A.; Lupinacci, L.; de la Mora Jimenez, E.; et al. Nivolumab plus Ipilimumab in Advanced Non-Small-Cell Lung Cancer. $N$ Engl J Med 2019, 381, 2020-2031, doi:10.1056/NEJMoa1910231.

26. 26. Paz-Ares, L.; Ciuleanu, T.E.; Cobo, M.; Schenker, M.; Zurawski, B.; Menezes, J.; Richardet, E.; Bennouna, J.; Felip, E.; Juan-Vidal, O.; et al. First-line nivolumab plus ipilimumab combined with two cycles of chemotherapy in patients with nonsmall-cell lung cancer (CheckMate 9LA): an international, randomised, open-label, phase 3 trial. Lancet Oncol 2021, 22, 198-211, doi:10.1016/S1470-2045(20)30641-0.

27. 27. Rizvi, N.A.; Cho, B.C.; Reinmuth, N.; Lee, K.H.; Luft, A.; Ahn, M.J.; van den Heuvel, M.M.; Cobo, M.; Vicente, D.; Smolin, A.; et al. Durvalumab With or Without Tremelimumab vs Standard Chemotherapy in First-line Treatment of Metastatic NonSmall Cell Lung Cancer: The MYSTIC Phase 3 Randomized Clinical Trial. JAMA Oncol 2020, 6, 661-674, doi:10.1001/jamaoncol.2020.0237.

28. 28. Sugawara, S.; Lee, J.S.; Kang, J.H.; Kim, H.R.; Inui, N.; Hida, T.; Lee, K.H.; Yoshida, T.; Tanaka, H.; Yang, C.T.; et al. Nivolumab with carboplatin, paclitaxel, and bevacizumab for first-line treatment of advanced nonsquamous non-small-cell lung cancer. Ann Oncol 2021, 32, 1137-1147, doi:10.1016/j.annonc.2021.06.004.

29. 29. Rodriguez-Abreu, D.; Powell, S.F.; Hochmair, M.J.; Gadgeel, S.; Esteban, E.; Felip, E.; Speranza, G.; De Angelis, F.; Domine, M.; Cheng, S.Y.; et al. Pemetrexed plus platinum with or without pembrolizumab in patients with previously untreated metastatic nonsquamous NSCLC: protocol-specified final analysis from KEYNOTE-189. Ann Oncol 2021, 32, 881-895, doi:10.1016/j.annonc.2021.04.008.

30. 30. Socinski, M.A.; Nishio, M.; Jotte, R.M.; Cappuzzo, F.; Orlandi, F.; Stroyakovskiy, D.; Nogami, N.; Rodriguez-Abreu, D.; Moro-Sibilot, D.; Thomas, C.A.; et al. IMpower150 Final Overall Survival Analyses for Atezolizumab Plus Bevacizumab and Chemotherapy in First-Line Metastatic Nonsquamous NSCLC. J Thorac Oncol 2021, 16, 1909-1924, doi:10.1016/j.jtho.2021.07.009.

31. 31. Yang, Y.; Sun, J.; Wang, Z.; Fang, J.; Yu, Q.; Han, B.; Cang, S.; Chen, G.; Mei, X.; Yang, Z.; et al. Updated Overall Survival Data and Predictive Biomarkers of Sintilimab Plus Pemetrexed and Platinum as First-Line Treatment for Locally Advanced or Metastatic Nonsquamous NSCLC in the Phase 3 ORIENT-11 Study. J Thorac Oncol 2021, 16, 2109-2120, doi:10.1016/j.jtho.2021.07.015.

32. 32. Wang, J.; Lu, S.; Yu, X.; Hu, Y.; Sun, Y.; Wang, Z.; Zhao, J.; Yu, Y.; Hu, C.; Yang, K.; et al. Tislelizumab Plus Chemotherapy vs Chemotherapy Alone as First-line Treatment for Advanced Squamous Non-Small-Cell Lung Cancer: A Phase 3 Randomized Clinical Trial. JAMA Oncol 2021, 7, 709-717, doi:10.1001/jamaoncol.2021.0366.

33. 33. Lu, S.; Wang, J.; Yu, Y.; Yu, X.; Hu, Y.; Ai, X.; Ma, Z.; Li, X.; Zhuang, W.; Liu, Y.; et al. Tislelizumab Plus Chemotherapy as First-Line Treatment for Locally Advanced or Metastatic Nonsquamous NSCLC (RATIONALE 304): A Randomized Phase 3 Trial. J Thorac Oncol 2021, 16, 1512-1522, doi:10.1016/j.jtho.2021.05.005.

34. 34. Zhou, C.; Wu, L.; Fan, Y.; Wang, Z.; Liu, L.; Chen, G.; Zhang, L.; Huang, D.; Cang, S.; Yang, Z.; et al. Sintilimab Plus Platinum and Gemcitabine as First-Line Treatment for Advanced or Metastatic Squamous NSCLC: Results From a Randomized, Double-Blind, Phase 3 Trial (ORIENT-12). J Thorac Oncol 2021, 16, 1501-1511, doi:10.1016/j.jtho.2021.04.011.

35. 35. Liu, L.; Bai, H.; Wang, C.; Seery, S.; Wang, Z.; Duan, J.; Li, S.; Xue, P.; Wang, G.; Sun, Y.; et al. Efficacy and Safety of FirstLine Immunotherapy Combinations for Advanced NSCLC: A Systematic Review and Network Meta-Analysis. J Thorac Oncol 2021, 16, 1099-1117, doi:10.1016/j.jtho.2021.03.016.

36. 36. Li, X.; Yan, S.; Yang, J.; Wang, Y.; Lv, C.; Li, S.; Zhao, J.; Yang, Y.; Zhuo, M.; Wu, N. Efficacy and Safety of PD-1/PD-L1 Inhibitors Plus Chemotherapy Versus PD-1/PD-L1 Inhibitors in Advanced Non-Small Cell Lung Cancer: A Network Analysis of Randomized Controlled Trials. Front Oncol 2020, 10, 574752, doi:10.3389/fonc.2020.574752.

37. 37. Turner, R.M.; Jackson, D.; Wei, Y.; Thompson, S.G.; Higgins, J.P. Predictive distributions for between-study heterogeneity and simple methods for their application in Bayesian meta-analysis. Stat Med 2015, 34, 984-998, doi:10.1002/sim.6381.

38. 38. Woods, B.S.; Hawkins, N.; Scott, D.A. Network meta-analysis on the log-hazard scale, combining count and hazard ratio statistics accounting for multi-arm trials: a tutorial. BMC Med Res Methodol 2010, 10, 54, doi:10.1186/1471-2288-10-54.

39. 39. Brooks, S.P.; Gelman, A. General Methods for Monitoring Convergence of Iterative Simulations. Journal of Computational and Graphical Statistics 1998, 7, 434-455, doi:10.1080/10618600.1998.10474787.

40. 40. Salanti, G.; Ades, A.E.; Ioannidis, J.P. Graphical methods and numerical summaries for presenting results from multipletreatment meta-analysis: an overview and tutorial. J Clin Epidemiol 2011, 64, 163-171, doi:10.1016/j.jclinepi.2010.03.016. 
41. 41. Paz-Ares, L.G.; Ramalingam, S.S.; Ciuleanu, T.E.; Lee, J.S.; Urban, L.; Caro, R.B.; Park, K.; Sakai, H.; Ohe, Y.; Nishio, M.; et al. First-Line Nivolumab Plus Ipilimumab in Advanced NSCLC: 4-Year Outcomes From the Randomized, Open-Label, Phase 3 CheckMate 227 Part 1 Trial. J Thorac Oncol 2021, doi:10.1016/j.jtho.2021.09.010.

42. 42. Leighl, N.B.; Laurie, S.A.; Goss, G.D.; Hughes, B.G.M.; Stockler, M.; Tsao, M.S.; Hwang, D.M.; Joubert, P.; Kulkarni, S.; Blais, N.; et al. CCTG BR34: A randomized phase II trial of durvalumab and tremelimumab +/- platinum-based chemotherapy in patients with metastatic non-small cell lung cancer. J Thorac Oncol 2021, doi:10.1016/j.jtho.2021.10.023.

43. 43. Boyer, M.; Sendur, M.A.N.; Rodriguez-Abreu, D.; Park, K.; Lee, D.H.; Cicin, I.; Yumuk, P.F.; Orlandi, F.J.; Leal, T.A.; Molinier, O.; et al. Pembrolizumab Plus Ipilimumab or Placebo for Metastatic Non-Small-Cell Lung Cancer With PD-L1 Tumor Proportion Score $>/=50 \%$ : Randomized, Double-Blind Phase III KEYNOTE-598 Study. J Clin Oncol 2021, 39, 2327-2338, doi:10.1200/JCO.20.03579.

44. 44. Apetoh, L.; Ladoire, S.; Coukos, G.; Ghiringhelli, F. Combining immunotherapy and anticancer agents: the right path to achieve cancer cure? Ann Oncol 2015, 26, 1813-1823, doi:10.1093/annonc/mdv209.

45. 45. Zitvogel, L.; Galluzzi, L.; Smyth, M.J.; Kroemer, G. Mechanism of action of conventional and targeted anticancer therapies: reinstating immunosurveillance. Immunity 2013, 39, 74-88, doi:10.1016/j.immuni.2013.06.014.

46. 46. Wang, J.; Fei, K.; Jing, H.; Wu, Z.; Wu, W.; Zhou, S.; Ni, H.; Chen, B.; Xiong, Y.; Liu, Y.; et al. Durable blockade of PD-1 signaling links preclinical efficacy of sintilimab to its clinical benefit. MAbs 2019, 11, 1443-1451, doi:10.1080/19420862.2019.1654303. 